\title{
WT1-A10/AS01B Immunotherapeutic GSK2130579A
}

National Cancer Institute

\section{Source}

National Cancer Institute. WT1-A10/AS01B Immunotherapeutic GSK2130579A. NCI

Thesaurus. Code C78865.

An immunotherapeutic consisting of the recombinant fusion protein WT 1-A10 combined with the adjuvant ASO1B with potential immunostimulating and antineoplastic activities. Upon administration, WT1-A10/AS01B immunotherapeutic GSK2130579AWT1 may induce a WT 1-specific cytotoxic T-lymphocyte (CTL) response ag ainst WT 1-expressing tumor cells, resulting in cell lysis and the inhibition of cellular proliferation. The tumorassociated antigen WT 1 (Wilms tumor protein-1) is overexpressed in most types of leukemia and in a variety of solid cancers. WT 1-A10 is a 292 amino acid recombinant fusion protein consisting of a 12-mer truncated tat sequence (leader sequence) and amino acids number 2-281 of the WT1 sequence; ASO1B consists of a combination of the adjuvants monophosporyl lipd A (MPL) and Q21. 